loosely in the bracket $\mathrm{J}$; this wheel is caused to revolve, and thus the supplementary valve raised or lowered by the handle $\mathrm{k}$, and shaft $\mathrm{L}$, and the additional bevel wheels.

The object of the invention is to arrest, more or less, as circumstances require, the passage of the steam through the equilibrium valve from one side of the piston to the other, and, consequently, of regulating the descent of the plunger.

The utility of the arrangement will be at once apparent; it obviates the necessity of adopting the old and tedious process of adding and removing heavy weights, while, in case of any breakage, or other accident occurring to the pumps in a mine, the damage likely to occur from sudden shocks is prevented by the facility of adjusting the valve to regulate the descent of the plungers.

It is in Cornish engines, when used for water works, however, where the utility of this invention may be brought into practice most advantageously, especially in those works where a stand pipe is used to obtain the necessary head of water; in this case the fluctuation in the level of water is necessarily sudden, and of considerable extent, causing a similar variation of load on the engines, and rendering the machinery most unsafe and uncertain in its action.

Should the head of water in the stand pipe be low, the plunger would have a tendency to descend with a dangerous rapidity, which is checked in a moment by turning the handle $\mathrm{K}$, so as to raise the supplementary valve $F$, thereby arresting the steam on its passage from one side of the piston to the other, the plunger consequently descending with a safe and gradual motion.

Should the head of water, on the contrary, be high, the valve $\mathrm{F}$ is instantly withdrawn from the seat, and a free passage given to the steam, the head of water being in itself sufficient to ensure an easy descent of the plunger.

Although the apparatus is shown in the sketch as regulated by hand, it is proposed in some instances to allow the variations in the head of the water to be the means of adjustment, an application which might be made by a simple arrangement of machinery.

It is, I am informed, Mr. Birkinbine's intention to apply his supplementary valve to the large engines he is now erecting for the West Philadelphia Water Works.

Stockton House, Philada., Jan. 10th, 1854.

For the Journal of the Franklin Institute.

The French Line-of-Battle Screw Steamship Charlemagne. By B. F. Isherwood, Chief Eng., U. S. N.

The Charlemagne is an old French ship of war, altered to a screw propeller steamship, in 1851, in accordance with the plans of Mr. Barnes. After this transformation, she was tried by a government Commission, which experimented with her in the Mediterranean, between Toulon and Spezzia, and from whose report, principally, the following elementary data was obtained; where it was deficient, I have completed it from other 
half hour the number of revolutions made by the screw, as registered by the counter; the pressure of the steam as indicated by two gauges placed on the steam pipes; the amount of opening of the throttle valves, the point at which the steam was cut off in the cylinders, the quantity of coal consumed, the speed by log, and, finally, the state of the wind and sea.

The mean effective pressure throughout the stroke of pistons was obtained by an indicator, but the Commission, in presenting their results, subtracted from that gross mean effective pressure $1 \frac{1}{2}$ pound per square inch of pistons for the friction of the machinery, and gave the remainder as the mean effective pressure in their report. 'This $1 \frac{1}{2}$ pound per square inch I have restored, and have made the friction deduction in another wanner, which I consider to be more exact.

Table of Resulls of the Trials of the Charlemagne.

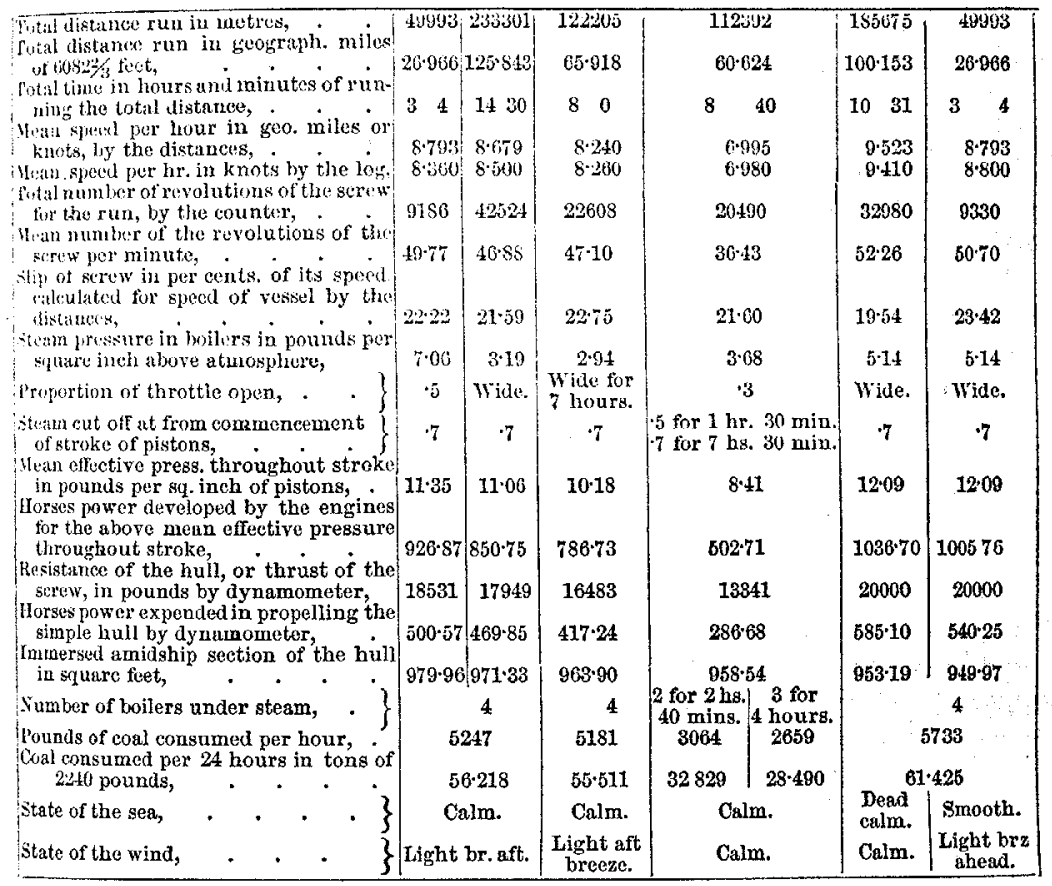

Friction of the Screw Surface on the Water.-The foregoing data allows a calculation to be made of the power absorbed by the friction of the screw surface on the water. For this purpose the data will be taken from the 5th, or next to the last column of the above Table of Results, because as in that column will be found the most profound calm of wind and sea, no corrections will be required for a disturbed state of those elementis.

The power required to overcome the friction of the engines, as ascertained by actual experiment on an engine of about the same size and speed of piston as one of the Charlemagne's, will be taken at 1.25 pound per square inch of pistons, and the ccefficient for the friction of the load, 
according to Morin's experiments, at 0.075 , which, as the mean effective pressure is 12.09 pounds per square inch, will be $(12.09 \times 0.075=) 0.91$ pound per square inch, making a total of $(1 \cdot 25+0 \cdot 91=) 2 \cdot 16$ per square inch for the friction resistances of the engines and load, which is $\mathbf{1 7 . 8 7}$ per centum of the total power developed by the engines, or $185 \cdot 26$ horse power. The power employed in the propulsion of the simple hull was $585 \cdot 10$ horses by dynamometer, and as pressure and resistance are equal and in opposite directions, the power lost in slip will bear to that utilized in the propulsion of the vessel the same ratio that the speed of the slip (or in other words, the velocity with which the water is driven back by the recession of the screw) bears to the speed of the vessel. Now, the slip of the screw was 19.54 per centum of its speed, leaving the speed of the vessel to be expressed by $(100 \cdot 00-19 \cdot 54 \Rightarrow) 80 \cdot 46$; therefore, as $80 \cdot 46: 19 \cdot 54:: 585 \cdot 10: 142 \cdot 09$, the horses power lost by the slip of the screw. After deducting the power $585 \cdot 10$ horses employed in propelling the simple hull, the power $142 \cdot 09$, horses lost in slip, and the power $185 \cdot 26$ horses expended on the friction resistances of the engines and load - total, 912.45 horses, from the total power 1036.70 horses developed by the engines, there remains $(1036 \cdot 70-912 \cdot 45 \Rightarrow 124 \cdot 25$ horses power, which is the amount absorbed by the friction of the screw surface on the water.

Collecting the above, we have the following disposition of the power, viz :-

\begin{tabular}{|c|c|c|c|c|}
\hline & & \multicolumn{2}{|c|}{ Horses Power. } & Per Centum. \\
\hline Propelling the simple hull of the vessel & & $585 \cdot 10$ & or & $56 \cdot 44$ \\
\hline Expended in the slip of the screw, & • & $142 \cdot 09$ & “ & $13 \cdot 70$ \\
\hline Expended in the friction of the screw, & & $124 \cdot 25$ & “ & 11.99 \\
\hline Expended in the friction of the engines & 5 and load, & $185 \cdot 26$ & “ & $17 \cdot 87$ \\
\hline 'Totals, & . & $1036 \cdot 70$ & or & $100 \cdot 00$ \\
\hline
\end{tabular}

Explanatory of the Losses of Power by Slip of the Screw.-In observing the above disposition of the power, a clear distinction must be kept in view between the power expended in the slip of the screw, 142.09 horses, or 17.87 per centum of the total power developed by the engines, which is the amount of power employed in merely giving a backward motion to the water passed by the screw, and the power actually caused to be lost by the slip of the screw. This latter is equal to the per centum of the screw's slip, and in the present case would amount to 19.54 per centum of the total power 1036.70 horses developed by the engines, or to 202.57 horses power : because by the reason of the screw having a slip of 19.54 per centum, and as the mean effective steam pressure on the engines' pistons continues the same, the speed of the engines has to be $19 \cdot 54$ per centum greater to give the ressel an equal speed in equal times than if there were no slip. Of course, this causes a loss of 19.54 per centum of the power required to work the engines-of the power expended in the friction of the screw surface on the water, and in the power required to propel the simple hull of the vessel. But the sum of the powers non-utilized, viz: those expended in slip, in friction of the screw, and engines, and load, total $451 \cdot 60$ horses, will remain the same, however divided; and the power 585.10 horses utilized in the propulsion of the vessel, will corssequently remain the same also. 
The foregoing disposition of the power, in connexion with the following table of calculations on the screw of the Charlemagne, enables us to determine the friction in the pounds avoirdupois of the square foot of the screw surface moving in its helical path with the velocity of 10 feet per second. For this purpose, the screw surface in the following table has been divided into a number of parallel strips, or elements, 0.25 foot wide; the length of the central helix of each of these elements has been taken as the length of the element, and the " expression for the friction of each element" has been computed separately as the friction is in the ratio of the squares of the relocities. 'This calculation for the expression of the friction has been made for convertibility into horse power, supposing the friction of each square foot moving with a velocity of ten feet per second to be an unit of weight. After the total friction of the screw for a speed of ten feet per second has been ascertained in horses power for a unit of weight, it is easily resolvable into the true friction in pounds, by dividing it into the "friction of the screw surface on the water" in horses power, as ascertained by the preceding " deposition of the power." For the rest, the table of calculations carries its own explanation.

This determination being made, gives for the value of the friction of one square foot of screw surface moving through water, in its helical path, with a velocity of ten feet per second, 0.7796 pound avoirdupois.

Calculations on the Screw of the Charlemagne.

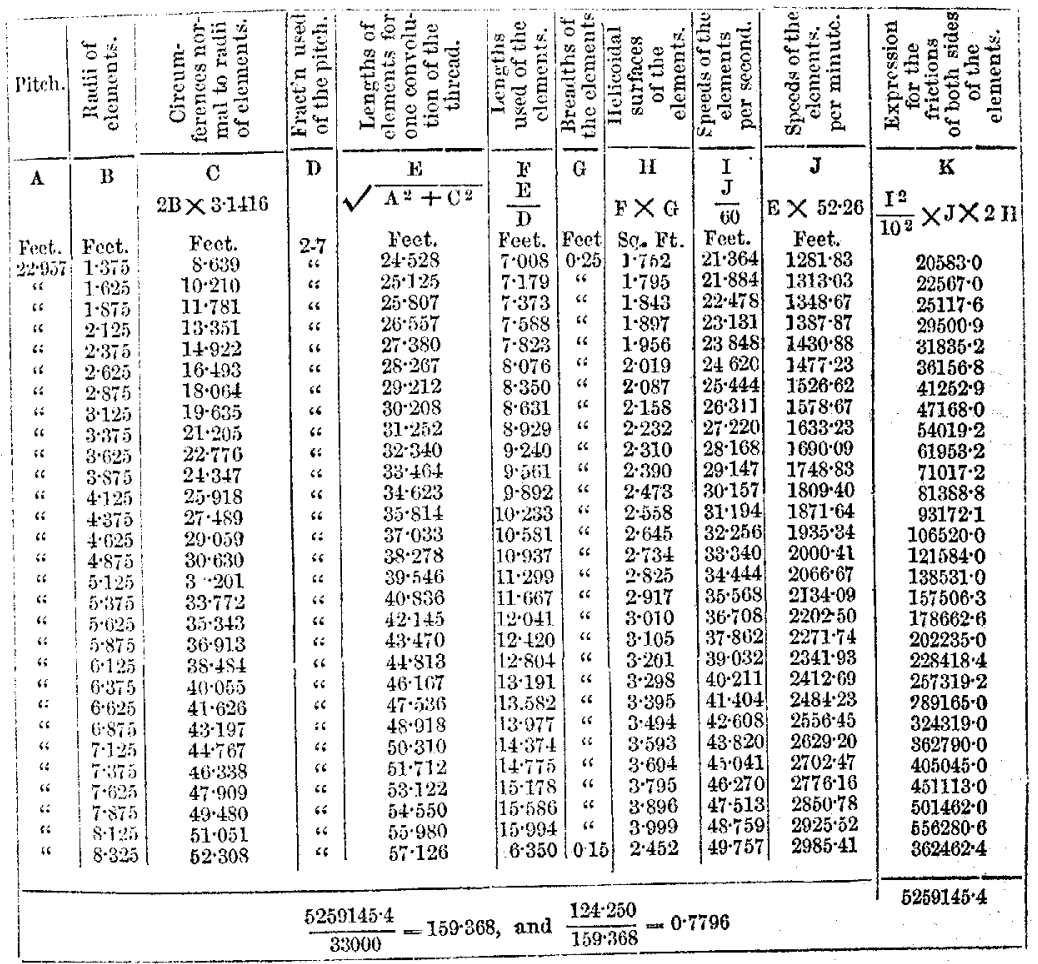

Voc. XXVIT.-Thind Series.-No. 2.-FenRoarx, 1854. 
Relation between the Piston Pressure and the Thrust of the Screw.-It is evident that, in general, every pressure or power must be balanced by an equal and opposite resistance. 'The mechanical effect of a pressure is estimated by multiplying that pressure by the space through which it acts; and the mechanical effect of a resistance is estimated by multiplying that resistance by the space through which it acts. Hence, any pressure exerted on the piston of a steam cylinder, and multiplied by the space through which it acts in a given time, must exactly equal or balance the resistance multiplied by the space through which it acts in the same time. It is plain that this general law is entirely independent of the absolute velocities of the pressure and resistance, and that the equality will always obtain, be those absolute velocities relatively what they may.

Let us apply the above to the case of a screw actuated by a steam engine, and propelling a vessel; and let us first examine the manner in which the power of the engine is employed, premising that we know the total indicator pressure on the pistons. That total pressure is the primitive force of the steam, without loss from its transmission by the machinery. That transmission, however, cannot be effected without one loss common to all machinery, and independent of any waste in function of the machine itself, viz: the loss by friction. It is plain, that before the engine can move at all-that is, before it can develope power-the pressure on the piston must be more than sufficient to overcome all the friction resistances acting against it. In the case of propelling a ressel by the screw, which is' a simple and perfect machine, operating no loss of useful effect in function of form, all these friction resistances will be the friction of the engine, per se, the friction of the load, and the friction of the screw surface on the water. It is then only what remains of the tota! piston pressure after deducting all these friction resistances, which is transmitted by the engine to the screw for the propulsion of the vessel; the application of this remainder of the pressure causes the screw to revolve, and thus transmit this pressure to the water in which the screw acts. 'The screw, therefore, transmits to the water all the pressure it received from the engine, and this pressure will, for one revolution of the screw, act through the length of the screw's pitch. Hence, the resistance per revolution of the screw will equal the pressure in pounds exercised by (or the result of) the screw, multiplied by the pitch of the screw, or the distance through which the resistance acts per revolution of the screw. From the foregoing it is also clear, that the power excrted to balance this resistance will be that aggregate pressure in pounds on the piston, which is left after deducting for all the friction resistances, multiplied by the space through which it acts; while the screw is making one revolution. 'This space will be the length of a double stroke of piston, when the engine is connected directly to the screw shaft without gearing.

From the above it is also plain, that the more or less slip of the screw does not modify or destroy the equality stated, becanse as the pressure of the screw is simply upon the water, it is immaterial whether the water on which the screw presses yields, and is forced back by the screw, (to which the name of slip is given,) or whether it remains unyielding, and the screw advances forward with any load whatever attached-the ves- 
sel for instance-therefore, the pressure or thrust of the screw in both cases must evidently be the same, because it is solely the effect of, and must be balanced by the piston pressure. Hence also follows, that the pressure exercised by the screw upon the yielding water, must also exartly equal the pressure exercised by the screw upon the vessel in forcing it forward; consequently the power transmitted by the engine to the screw will be divided relatively between the slip of the screw and the propulsion of the vessel, in the ratio of the spaces through which the slip recedes and the vessel advances in equal time. 'Thus it is seen that weither the slip of the screw, nor the absolute speed of the screw, engine pistons, or vessel, can modify or destroy the equality subsisting between the thrust of the screw and the pressure on the pistons.

From all the foregoing, then, we derive that the thrust of the screw in pounds, by dynamometer, multiplied by the space through which that thrust acts in a given time, is always equal to what remains of the total piston pressure after deduction has been made of the pressure required for overcoming all the friction, resistance of engine, load, and screw surface on the water, mulliplied by the space through which said remainder of piston pressure acts in the same time.

The experiments with the Charlemagne, are arranged in the Table of Results, in six columns, and were made with different velocities of engines' pistons, and of vessel. They will furnish a very good practical iest, not only of the truth of the above law, but also of the accuracy of both the observed data and of the calculation based on it. The Charlemagne has four steam pistons, whose aggregate area amounts to 8251.6 square inches; the length of the double stroke of piston is 6.562 feet. The pitch of the screw is 22.957 feet, and the screw makes one revolution to each double stroke of piston.

The computation for the pressure required to overcome the friction resistance for the following different volumes, has been made from the data of the 5th column. The pressure required to work the engine alone is taken to be the direct ratio of the speeds of the piston. The pressure required to overcome the friction of the load is taken at Morin's coefficient of 0.075 of the total indicator pressure. The pressure required to overcome the friction of the screw is taken to be in the ratio of the squares of the velocities of the screw. The following are the detailed results, viz:

\section{FIRST COLUMN.}

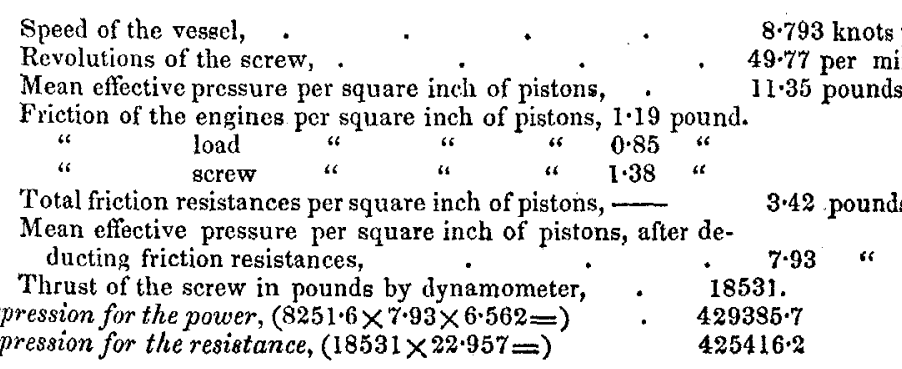


Sipeed of the ressel,

Revolutions of the screw, .

Mean elfetive pressure per square incl of pistons,

Friction of the engines per square inch of pistons, 1. I 2 pound.

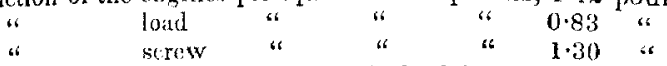

Total friction resistances per sryuare inch of pistons,

Mean elfeclive prossire per square inch of pistons, after deJucting friction mosistances,

Thrust of the serew in pouds by dynamometer,

Sixpression for the power, $(8251.6 \times 7.81 \times 6.562=)$

3.25 pounds.

Expression for the resistence, $(1.7949 \times 22.957=)$

$8 \cdot 679$ knots pr. lion. 46.88 per minute. $11 \cdot 06$ pounds. le-

\section{THIRD COLUMN.}

Speed of the visull,

Revolutions of ale screw,

Hean eflective pressure per square inch of pistons,

Friction of the engines per square inch of pistons, $1 \cdot 13$ pound.

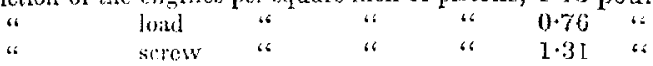

T'otal friction resistinces per square inch of pistons,

Mean eflective pressure per sguare inch of pistons, after de-

ducting friction resistances,

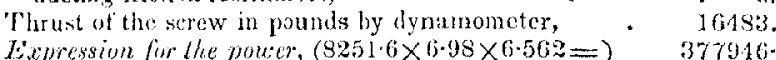

$\begin{array}{ll}\text { Expression fir the pouer, }(9251.6 \times(3.98 \times 6.502 \Rightarrow) & 377916 \cdot 1 \\ \text { Expression for the resistance, }(16183 \times 22.057=) & 375100.2\end{array}$

$8 \cdot 210$ knots pr. ligur. 47.10 per minutu.

10.1 s poumls.

\section{FOUR'TI COLUMN.}

Speed of the resed,

Revolutions of the serew,

Men efletive pressure per squarc incl of pistons,

Friction of the encrines per saluare inch of pistons, 0.87 pound.

$3 * 20$ pounds.

$6.95 \quad$.

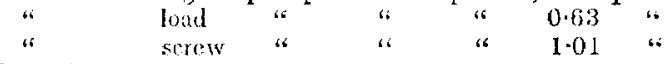

Fotal friction resistances persquare inch of pistons,--
Mean eftective pressure per square inch of pistons, after deductinur friction resistances,

'Thrust of the screw in pounds by dynamometer, 13341.

Expression for the power, $(8251.6 \times 5.9 \times 6.562=3) \quad 319467 \cdot 3$

Tixpression for the resistance, $(13341 \times 22.957=) \quad$. $\quad 306263.3$

6.995 knots pr. hour. 36.43 per minute. $8 \cdot 41$ pounds.

\section{FIFTI COLUMN.}

Speed of the vessel,

Revolutions of the screw,

Mean eflective pressure per square inch of pistons,

Friction of the engines per square inch of pistons, 1.25 pound.

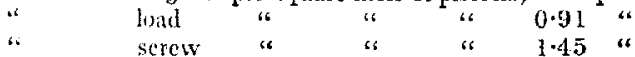

Total friction resistances per square inch of pistons,-

Hean eflective pressure per square inch of pistons, after deducting friction resistances,

Thrust of the screw in pounds by dynamometer,

Expression for the power, $(8251.6 \times 8.48 \times 6.562=)$

Lixprosion for the resistance, $(20000 \times 22.057=)$
$9 \cdot 523$ linots pr. liour. $52 \cdot 26$ per minute. $12 \cdot 09$ pounds.

3.61 pounds.

20000 . $459166 \cdot 6$ $4501+10 \cdot 0$ 


\section{SIXTH COLUMN.}

Speed of the ressel,

Revolutions of the screw,

Mean effective pressure per square inch of pistons,

Friction of the engines per square inch of pistons, 1.21 pound.

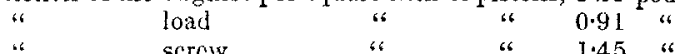

" $1.45 "$

Total friction resistance per square inch of pistons,-- $\quad 3.57$ pounds.

Mean effective pressure per square inch of pistons, after deducting friction resistances, . . 8.52 "

Thrust of the screw in pounds by dynamometer, . 20000.

Lixpression for the power, $(8251.6 \times 8.52 \times 6.562=) \quad 461332.4$

Expression for the resistance, $(20000 \times 22.957=)$. 459140.0

The reader will not fail to observe how very closely in each case the "expression for the power" agrees with the "expression for the resistance."

It also follows from the foregoing law, that the thrust of the screw is aiways in the direct ratio of the effective piston pressure, and that it will always be the same with the same remainder of the piston pressure after reducting all the friction resistances, let the speed of the screw or the load upon it be what they may. It will be the same with the vessel under way, towing, or tied to the dock. This can be practically tested by iaking from the six trials with the Charlemagne the thrusts by the screw, and dividing them by the mean effective pressure that remains after deducting the friction resistances, when the quotients will be found to be nearly equal. Ind the data been exact, the quotients would have been exactly the same. The results are as follows, viz:

$\begin{array}{cc} & \text { Mean eflective } \\ \text { pressure in } \\ \text { Revolutions } & \text { pounds per } \\ \text { made by } & \text { square inch } \\ \text { the screw } & \text { on the pistons } \\ \text { per minute. after deducting } & \text { all the friction } \\ \text { resistances. }\end{array}$

Thrust of the screw in pounds by Dyna. mometer.

\begin{tabular}{|c|c|c|c|c|c|}
\hline ist columu, & 49.99 & $7 \cdot 93$ & 18531 & and & $\frac{18531}{7 \cdot 93}=2336.82$ \\
\hline 21 column & 46.88 & 7.81 & 17949 & $"$ & $\frac{17949}{7 \cdot 81}=2298 \cdot 21$ \\
\hline Bd column, & $19 \cdot 10$ & 698 & 16483 & “ & $\frac{16483}{6.98}=2361.46$ \\
\hline Ath column, & 3643 & $5 \cdot 90$ & 13341 & $"$ & $\frac{13341}{5 \cdot 90}=2261 \cdot 18$ \\
\hline 5th column, & $52+26$ & 8.48 & 20000 & $"$ & $\frac{20000}{8 \cdot 48}=2358 \cdot 49$ \\
\hline h column, & $50 \cdot 90$ & $8 \cdot 52$ & 20000 & " & $\frac{20000}{8 \cdot 52}=2347 \cdot 42$ \\
\hline
\end{tabular}

Evaporation by the Boiler.-An experiment was 'made to ascertain whether any economy in fuel would be effected by slower combustion, and using more boiler. The result is given in the 4th column of the 'Table of Results, and it was found that by hard firing and burning at the rate of 32.829 tons of coal per 24 hours, two boilers could be made to 
produce sufficient steam to maintain a boiler pressure of $3 \cdot 68$ pounds per square inch above the atmosphere, with 36.43 revolutions of the screw per minute; while with three boilers, or 50 per centum more, the same amount of steam was furnished by burning at the rate of 28.490 tons of roal per 24 hours, or $13 \frac{\mathrm{r}}{5}$ per centum less than the former amount, (32.829 tons.)

The following evaporation by the boilers has been calculated from the mean of the data in the 5th and 6 th columns of the Table of Results, where the throttles were carried wide. The steam pressure in the cylinders, before cutting off (at $\frac{7}{10}$ the stroke from the commencement), averaged 1.6 pound per square inch above the atmosphere. The sleam space comprised in the cylinder nozzles, clearance, \&c., at one end of the four cylinders, is taken at 10 cubic feet. The loss by blowing-off is i:alculated for maintaining the sea-water in the boilers at twice the natural concentration, and is included in the evaporation. The temperature of the feed water is taken at $100^{\circ}$ Fahr. Double stroke of pistons 51.78 per minute, and Regnault's determination of the latent heat of steam is used. The following are the results, viz :

Cubic feet of stean of atmospheric pressure furnished per minute under the above conditions,

Pounds of steam evaporated per hour by one pound of coal under? the above conditions,

$18070 \cdot \% 4$

Under the ordinary conditions of practice, there would be found a considerable decrease of the above evaporation, reducing the units of steam to about 6.50 per unit of coal, instead of 6.95 ; because during the above r:xperiment, the longest run being only $14 \frac{1}{2}$ hours, and the run from which the data is taken only $10 \frac{1}{2}$ hours, there could have been but very little, if any, cleaning of fires, and also much less blowing-off, than in a long run of days, as the vessel would start with full boilers of sea-water of the natural concentration.

\section{For the Journal of the Franklin Institute.}

\section{Dudgeon's Patent Hydraulic Press.}

'This ingenious and useful apparatus was patented July 8th, 1852, and is becoming extensively introduced as a substitute for the old jack screw. The advantages it possesses are, 1st, Its lightness, which makes it ersy tor one man to shoulder a press capable of raising ten tons. $2 \mathrm{~d}$, The small power required to work it, every press being arranged so that one man can raise the weight for which the press is calculated. This advantage must be obvious, when we reflect that the friction of the old jack screw, which is enormous, particularly when the oil has been gummed by cold or dirt, is replaced by the very trifling friction incident to the passage of the fluid in the press through the openings. $3 \mathrm{~d}$, The ease with which heavy bodies may be lowered, which may be effected slowly or rapidly, as desired, by simply touching the relief valve with the working lever. 4 th, The convenience of using it in confined situations, where it is difticult or impossible to turn the lever of the screw. To those who are accustomed to the use of the jack screw, and who are therefore acquainted with its inconveniences, the advantages of this press will be evident. 